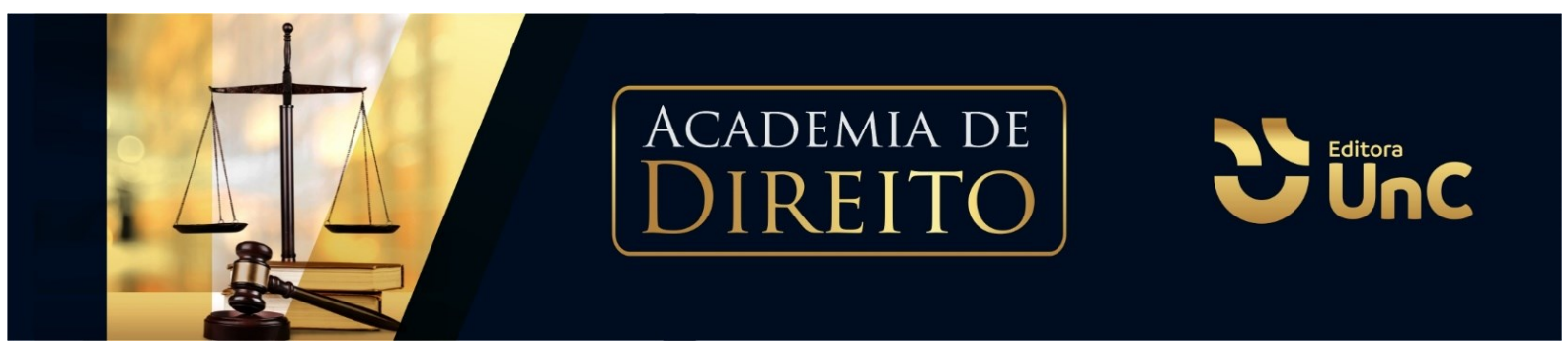

\title{
A INCONSTITUCIONALIDADE DA CRIMINALIZAÇÃO DA POSSE DE DROGAS PARA CONSUMO PESSOAL
}

\author{
THE UNCONSTITUTIONALITY OF CRIMINALIZATION OF DRUGS FOR
}

PERSONAL USE

Jaine Dobrychtop ${ }^{1}$

Eduardo Borges ${ }^{2}$

\begin{abstract}
RESUMO
O presente trabalho tem como finalidade discutir a criminalização da posse de drogas para consumo pessoal. O problema proposto é como a tipificação dessa conduta pode ferir princípios consolidados na Constituição Federal. A metodologia utilizada foi a pesquisa bibliográfica e jurisprudencial. Utilizou-se como critérios de delimitação o art. 28 da Lei 11.343/2006, as decisões dos tribunais brasileiros e a Constituição Federal brasileira. Por fim, examinou-se o Recurso Extraordinário n. 635.659, abordando os votos até então proferidos pelos ministros da Suprema Corte. Com essas análises, tem-se que uma pessoa não deve sofrer reprovação penal por uma conduta autodestrutiva. É de extrema importância evidenciar que a criminalização da posse de drogas para consumo pessoal viola a dignidade da pessoa humana, bem como a autonomia de escolha, a liberdade, entre outros direitos fundamentais. Resta evidente, de acordo com o posicionamento de parte da doutrina, bem como alguns ministros do Supremo Tribunal Federal de que é inconstitucional o art. 28 da Lei de Drogas.
\end{abstract}

Palavras-Chave: Posse de drogas para consumo pessoal. Lei de Drogas. Princípios constitucionais. Inconstitucionalidade.

\begin{abstract}
The aim of the present study is to discuss the criminalization of drug possession for personal use. The problem proposed is how the typification of this conduct can hurt principles consolidated in the Federal Constitution. The methodology used was bibliographic and jurisprudential research. The delimitation criteria used were the section 28 of Law 11.343/2006, the decisions of the Brazilian courts and the Brazilian Federal Constitution. Finally, examination of Extraordinary Appeal no. 635,659, addressing the votes so far handed down by Supreme Court ministers. With these analyzes, it follows that a person should not suffer criminal reproach for self-destructive conduct. It is extremely important to highlight the criminalization of the possession of drugs for personal consumption violates the dignity of the human person, the autonomy

\footnotetext{
${ }^{1}$ Graduanda em Direito pela Universidade do Contestado Campus Mafra. Santa Catarina. Brasil. E-mail: jaine.dobrychtop@aluno.unc.br

${ }^{2}$ Mestre em Direito Administrativo pela Universidade do Contestado (UnC). Docente da Universidade do Contestado Campus Mafra. Santa Catarina. Brasil. E-mail: eduardo.borges@professor.unc.br.
} 
of choice, the freedom, among other fundamental rights. It remains evident, according to the position of part of the doctrine, also, as some ministers of the Supreme Federal Court that section 28 of the Drug Law is unconstitutional.

Keywords: Possession of drugs for personal use. Drug Law. Constitutional principles. Unconstitutionality.

\section{INTRODUÇÃO}

O presente trabalho tem como objetivo analisar a constitucionalidade do crime da posse de drogas para consumo pessoal em face aos princípios constitucionais da dignidade da pessoa humana, igualdade e isonomia, objetivos fundamentais da República, que funcionam como limites ao legislador.

A pesquisa procura encontrar uma resposta ao seguinte problema: diante dos princípios fundamentais da dignidade da pessoa humana, intimidade, vida privada e liberdade, é constitucional dispositivo legal que define como crime a posse de drogas para consumo pessoal?

O objetivo geral consiste em analisar a constitucionalidade na criminalização da posse de drogas para consumo pessoal. Os objetivos específicos consistem em abordar os princípios constitucionais que regem o direito de escolha e de personalidade do indivíduo e abordar o conceito e a evolução legislativa de drogas no Brasil, analisando a constitucionalidade da criminalização da posse de drogas para consumo pessoal.

Para a realização da pesquisa foi utilizada a metodologia bibliográfica e jurisprudencial, bem como a análise em artigos científicos, legislação brasileira, decisões dos tribunais brasileiros e a Constituição da República Federativa do Brasil.

Em um primeiro momento explana-se sobre as drogas e a evolução legislativa correspondente no Brasil, seguindo de uma análise do art. 28 da lei de drogas, com diferenciação entre a figura do usuário e do traficante e as medidas impostas para cada.

Em um segundo momento, apresentam-se os princípios constitucionais concernentes à discussão proposta e sua correlação com a constitucionalidade do art. 28 da lei $11.343 / 2006$.

Após, apresenta-se a análise da constitucionalidade da proibição da posse de drogas para consumo pessoal, sob a luz dos direitos fundamentais. Por fim, examinou- 
se o Recurso Extraordinário $n .^{\circ} 635.659$, comparando os votos até então proferidos pelos ministros da Suprema Corte.

\section{CONCEITO DE DROGAS}

De drogas há numerosos conceitos que não se limitam a defini-la, porém refletem aspectos históricos, econômicos, científicos e morais. Não há que se falar em uma acepção unicamente jurídica do termo devido a generalidade na sua caracterização.

Segundo o observatório brasileiro de informações sobre drogas, a origem etimológica da palavra droga advém de drogg, que se originou na Holanda antiga e tem o significado de folha seca. Sem dúvidas muitos dos medicamentos daquela época utilizavam vegetais em sua composição (PAULINO, 1999).

No cenário atual, a definição mais comum no meio científico é aquela proposta pela Organização Mundial da Saúde, sob uma perspectiva biológica, "droga é toda substância natural ou sintética que introduzida no organismo vivo, pode modificar uma ou mais de suas funções" (OMS, 1993, p. 69).

Segundo a doutrina, droga é toda substância natural ou sintética, suscetível de criar: a) um efeito sobre o sistema nervoso central; b) uma dependência psíquica ou física; c) um dano a saúde pública e social (GRECO FILHO; RASSI, 2007).

Para Andreucci (2007), consideram-se drogas todas as substâncias ou produtos com potencial de causar dependência, desde que estejam indicadas em dispositivo legal competente.

Conforme previsto na legislação brasileira n. 11.343/2006, droga tem a seguinte definição:

Art. $1^{\circ}[\ldots]$ Parágrafo único. Para fins desta Lei, consideram-se como drogas as substâncias ou os produtos capazes de causar dependência, assim especificados em lei ou relacionados em listas atualizadas periodicamente pelo Poder Executivo da União (BRASIL, 2006).

Em análise ao artigo supracitado, é possível verificar que existe norma penal em branco quanto a lista das substâncias ilícitas. Diante disso, conforme art. 66 da Lei 11.343/2006, deve-se usar a lista contida na Portaria $\mathrm{n}^{\circ} 344$, de 12 de maio de 1998, 
do Ministério da Saúde (BRASIL, 2006). As demais substâncias ou produtos com potencial de causar dependência que não constem na Portaria, não serão consideradas drogas para fins penais. É o que ocorre, por exemplo, com as bebidas alcoólicas.

\section{EVOLUÇÃO LEGISLATIVA SOBRE DROGAS NO BRASIL}

Desde o início do século XX, o tráfico e o consumo de substâncias ilícitas têm causado grande preocupação mundial. Diante dos malefícios a saúde e a ordem pública causados pelas drogas, o Estado usa o direito de punir para proteger o equilíbrio social.

No Brasil, de acordo com Vicente Grego Filho e João Daniel Rassi (2007), a primeira legislação que previa a punição para o uso e comercio de entorpecentes está nas ordenações Filipinas, de 1603.

A lei foi promulgada por Filipe II em 1603, e fazia menção ao porte, consumo e a venda de substâncias tidas como tóxicas, no Título LXXXIX. As penas aplicadas eram severas, e previam a pena de morte e o exílio. A escolha da sanção aplicável ficava ao arbítrio do julgador (BITENCOURT, 2017).

Mais de duzentos anos depois, com a elaboração do código de 1890, voltou-se a tratar das substâncias ilícitas com a criação de dispositivo que previa como crime "expor à venda ou ministrar substanciais venenosas sem autorização e sem formalidades previstas nos regulamentos sanitários" (PIERANGELI, 2001, p. 200).

Diante da ineficiência da legislação para combate ao uso de drogas, sobreveio o Decreto n. 4294/1921, impulsionado pela Convenção de Haia de 1921. Diante da precariedade nos resultados, o decreto sofreu diversas alterações, com edições nos anos de 1932 e 1938 (GRECO FILHO; RASSI, 2007).

Em 1940, após passar por uma comissão revisora, o projeto de Alcântara Machado foi sancionado como Código Penal. Este estabelecia medidas contra o comércio clandestino e a facilitação de uso de entorpecentes (RANGEL; BACILA, 2015).

Ainda, em 1941, foi criada a Comissão Nacional de Fiscalização de Entorpecentes, pelo Decreto-Lei n. 3.114, o qual tratou de normas gerais para cultivo, 
extração e purificação de princípios ativo-terapêuticos de plantas entorpecentes (GRECO FILHO; RASSI, 2007).

Posteriormente, em 1964, foi criada a lei 4.451, a qual modificou o artigo 281 do Código Penal para incluir a ação de plantar. A matéria foi alterada após por decretos em 1968 e 1971. Em dezembro de 1976, foi sancionada a lei 6.368, a qual tratou de regulamentar a matéria do tráfico e uso de substâncias entorpecentes, substituindo a lei anterior (RANGEL; BACILA, 2015).

Os métodos utilizados pela Lei 6.368 para combater o tráfico e o uso dos entorpecentes contribuíram para o inchaço prisional, e assim, a lei não se mostrava mais eficaz, haja vista que tratava o traficante e o usuário como criminosos (SILVA, 2016).

Com a promulgação da Constituição em 1988, foi reafirmado a necessidade do tratamento diferenciado entre o usuário e o traficante de entorpecentes:

\footnotetext{
Ao entrarem vigor a Constituição de 1988 verificou-se que o tratamento diferenciado para os traficantes continuava em plena marcha. Por força de disposição constitucional o tráfico ilícito de entorpecentes e drogas afins passou a ser inafiançável e insuscetível de graça ou indulto (CARVALHO, 1997, p. 10).
}

A Lei n. 10.409/2002, buscou substituir a lei anterior por completo. Ocorre que, devido a péssima qualidade na definição dos crimes, o Capítulo III foi integralmente vetado, passando a vigorar em conjunto, as leis 6.368/76 e 10.409/02 (GRECO FILHO; RASSI, 2007).

A Lei 11.343, ainda vigente, foi publicada em 23 de agosto de 2006, e entrou em vigor em 08 de outubro do mesmo ano. $\mathrm{O}$ art. 75 da lei revogou expressamente a legislação anterior, desta forma, todos aqueles que estavam respondendo pelo crime do art. 16 da lei 6.368/76 passaram a ter direito de se submeter, caso mais benéfico, às novas sanções descritas no art. 28 da nova lei (RANGEL; BACILA, 2015).

Constata-se que a lei preferiu intensificar a repressão ao comércio e suavizar a resposta penal aos usuários, optando por estabelecer várias modalidades de penas aos usuários que, no entanto, jamais ocasionariam a prisão. 


\section{O ART. 28 DA LEI DE DROGAS E SUA NATUREZA JURÍDICA}

O art. 28 da Lei Antidrogas prevê várias condutas incriminadoras: adquirir, guardar, ter em depósito, transportar e trazer consigo substância ilícita (BRASIL, 2006).

Não há tipificação quanto ao uso da droga. Caso exame toxicológico constate que alguém fez uso de droga, ou caso alguém confesse o uso, não responderá pelo crime. No entanto, se for apreendido substância em que através da perícia se verifique a existência de princípio ativo droga, a conduta será tipificada como crime (GONÇALVES, 2011).

O sujeito ativo do crime pode ser qualquer pessoa que pratique uma das condutas descritas no tipo penal. Em se tratando de ato infracional, aplica-se as medidas socioeducativas do ECA, as quais não poderão ser mais graves que as previstas no art. 28 da Lei 11.343/06 (GOMES, 2006).

Há duas correntes que definem o bem jurídico tutelado no dispositivo. A primeira corrente entende que a saúde pública é a principal afetada por aqueles que praticam a conduta da posse de drogas para consumo pessoal; a segunda corrente defende que a conduta está ligada, unicamente, ao indivíduo que incorre na prática definida no tipo penal (ROSA, 2005).

Para Bacila e Rangel (2015), o bem jurídico tutelado pelo dispositivo é a saúde pública, visto que não há como criminalizar a autolesão ou o risco de autolesão. Desta forma, há uma presunção abstrata de perigo para terceiros.

Os autores Renato Marcão (2015) e Damásio de Jesus (2010), sustentam que a Lei não pune o consumo da droga, porque se assim o fizesse, violaria o princípio da alteridade e o dispositivo seria inconstitucional. Do ponto de vista material, o caráter criminoso se justifica devido o bem jurídico tutelado na norma ser a saúde pública.

Por outro lado, Maria Lúcia Karam (2006) adota a corrente inversa, e explica que a conduta da simples posse de drogas para consumo pessoal não fere a saúde pública, haja vista que não afeta nenhum bem jurídico de terceiro. Trata-se de conduta que atinge unicamente o indivíduo e as suas opções pessoais.

O elemento subjetivo da conduta é o dolo, ou seja, a vontade do agente é de ter a droga para o consumo próprio, o que, diante da ausência de critérios definidos 
na lei, é comprovado através das circunstâncias sociais e pessoais (RANGEL; BACILA, 2015).

O art. 28 da lei 11.343/06 prevê três penas alternativas para o delito: advertência sobre os efeitos das drogas; prestação de serviços à comunidade e medida educativa de comparecimento à programa ou curso educativo (BRASIL, 2006).

\begin{abstract}
Ao usuário não se comina pena de prisão. Pretende-se que ele nem sequer passe pela polícia. $O$ infrator da Lei será enviado diretamente aos Juizados Criminais, salvo onde inexistirem tais juizados em regime de plantão. Não há que se falar, de outro lado, em inquérito policial, sim em termo circunstanciado. Não é possível a prisão em flagrante. [...] Na audiência preliminar é possível a transação penal, aplicando-se as penas alternativas do art. 28. Não aceita (pelo agente) a transação penal, segue o rito sumaríssimo da Lei 9099/95. Mas no final, de modo algum será imposta pena de prisão, sim, somente as medidas alternativas do art. 28 (ANDREUCCI, 2007, p. 03).
\end{abstract}

A conduta da posse de drogas para consumo pessoal não recebe pena privativa de liberdade devido ao ordenamento jurídico-penal não punir a autolesão. As medidas impostas ao usuário são, inclusive, mais brandas do que as contravenções penais (NUCCl, 2013).

Encerrando a análise normativa acerca do usuário, a lei prevê no $\S 6^{\circ}$ do art. 28, que caso o autor do fato injustificadamente não cumpra as medidas impostas, o juiz poderá aplicar, sucessivamente, admoestação verbal e multa (BRASIL, 2006). Entretanto, não há previsão da aplicação da pena de privação da liberdade.

\title{
5 FIGURA DO USUÁRIO VERSUS TRAFICANTE
}

A diferenciação entre o usuário e o traficante se dá através da finalidade da droga apreendida. Conforme o texto legal, usuário é o consumidor eventual de droga, o qual, a partir da sua liberdade psíquica ou física busca ou não os efeitos da droga. Por outro lado, traficante é aquele que busca auferir vantagem econômica, de forma habitual ou eventual, através da venda da droga (SHECARIA, 2014).

Segundo Luiz Flávio Gomes (2013), para fins penais, após a vigência da lei 11.343/2006, usuário de drogas é quem adquire, guarda, tem em depósito, transporta ou traz consigo, para consumo pessoal, qualquer tipo de droga ilícita. 
Conforme art. $28, \S 2^{\circ}$ da Lei $11.343 / 2006$, para compreender se a destinação da droga era o consumo pessoal pelo autor do fato, o juiz deverá analisar a natureza e a quantidade da substância apreendida, o local e as condições da ação, bem como as circunstâncias sociais e pessoais, a conduta e os antecedentes do agente (BRASIL, 2006).

Segundo Guilherme Souza Nucci (2013), o traficante e o usuário estão sujeitos a penas distintas devido ao fato da proteção do legislador ao consumidor da droga. $\mathrm{O}$ usuário não recebe como sansão pena restritiva de liberdade, enquanto para o crime do tráfico é previsto pena de reclusão de 05 (cinco) a 15 (quinze) anos, além do pagamento de multa.

Ocorre que a não previsão de critérios específicos para tal diferenciação da margem a discricionariedade do Juiz, o qual estabelece seu próprio conceito de usuário e traficante, o que pode acarretar no aumento dos índices de encarceramento (SHECARIA, 2014).

Desse modo, como as penas impostas para o traficante e para o usuário são distintas, o Juiz deve analisar o caso concreto com muita atenção, para que a condenação esteja de acordo com o crime praticado.

\section{PRINCÍPIOS CONSTITUCIONAIS}

Há inúmeros princípios constitucionais que são aplicados as normas infraconstitucionais, os quais podem ser expressos ou tácitos. A Constituição Federal de 1988 é considerada um grande marco na conquista de direito e garantias individuais.

Os direitos fundamentais cumprem a função de limitar a interferência do ente estatal na esfera da vida privada dos indivíduos e em suas escolhas pessoais, desde que as ações não venham a ferir direitos alheios (MASSON, 2012).

Para a análise da constitucionalidade da criminalização da posse de drogas para consumo pessoal, serão ponderados exclusivamente os princípios da dignidade da pessoa humana, igualdade e isonomia, liberdade, intimidade e vida privada. 


\subsection{PRINCÍPIO DA DIGNIDADE DA PESSOA HUMANA}

O princípio da dignidade da pessoa humana está consagrado no artigo $1^{\circ}$, inciso III da Constituição Federal de 1988, que o aponta como fundamento da República (SARMENTO, 2016).

Segundo Agostini (2009, p. 01), com base no entendimento de Kant, dignidade pode ser definida como:

[...] um sentimento a priori, destinado apenas à pessoas; um sentimento que impede que os seres humanos sejam tratados simplesmente como um meio, isto é, que sejam manipulados, instrumentalizados; e que, fundado na reciprocidade entre os seres humanos requer desses, que podem exercer sua capacidade de moralidade, não tratar como meros meios aqueles que não podem, mas considerá-los como fins em si mesmos, isto é, como se estivessem em condições para tal.

A dignidade da pessoa humana se manifesta na livre escolha da própria vida, e traz consigo a pretensão ao respeito por parte de terceiros, de forma que, apenas excepcionalmente, possam ser feitas limitações ao exercício de direitos fundamentais, desde que não menosprezem o respeito que merecem todas as pessoas (MORAES, 2000).

A respeitabilidade mínima em relação ao homem independe de qualquer característica especial do ser humano, ou ainda, da idade, condição social, ascendência ou grau de hierarquia. Trata-se de tratamento digno, que decorre exclusivamente da sua existência (ZISMAN, 2005).

Ao definir os grupos com potencialidade delitiva, e ao destruir seus componentes do status de pessoa, renuncia-se a própria noção de Estado Democrático de Direito. A destituição da cidadania ocorre quando a segurança pública se sobrepõe à dignidade da pessoa humana (CARVALHO, 2010). Desse modo, é dever do Estado, da sociedade e de suas instituições assegurar a proteção de todas as pessoas e se omitir diante das escolhas dos indivíduos.

\subsection{PRINCÍPIO DA IGUALDADE E ISONOMIA}

Os princípios da igualdade e da isonomia estão protegidos como cláusulas pétreas pela Constituição no art. $5^{\circ}$, caput e inciso XLI. São direitos indisponíveis e 
irrenunciáveis que impedem qualquer forma de discriminação, os quais além de direitos individuais foram erigidos como objetivos fundamentais do nosso país pelo art. $3^{\circ}$, incisos III e IV da CF (BRASIL, 1988).

Tradicionalmente entende-se que a igualdade de todos perante a lei se refere à exigência de igualdade na aplicação da lei. As leis devem ser impostas sem ser levado em conta as pessoas que viessem a ser por elas alcançadas (LOPES, 1999).

Consequentemente, seria inconstitucional lei que impõem obrigação, dever, ônus, sanção ou qualquer sacrifício a pessoas ou grupo de pessoas, descriminandoas em face de outros na mesma situação de igualdade (SILVA, 2014).

Nesse sentido, afirma Salo de Carvalho (2010, p. 270):

\begin{abstract}
A ofensa ao princípio da igualdade estaria exposta no momento em que se estabelece distinção de tratamento penal (drogas ilícitas) e não-penal (drogas lícitas) para usuários de diferentes substâncias, tendo ambas potencialidades de determinar dependência física ou psíquica. A variabilidade da natureza do ilícito tornaria, portanto, a opção criminalizadora essencialmente moral.
\end{abstract}

Dessa forma, o legislador, ao tipificar a conduta da posse de drogas para consumo pessoal criou uma distinção entre usuários de substâncias licitas e ilícitas, sem qualquer justificação ou amparo constitucional, mas apenas com base na moral, a qual não deve ser confundida com direito.

\title{
6.3 PRINCÍPIO DA LIBERDADE
}

Conforme se extrai do art. $5^{\circ}$ da Constituição Federal, liberdade é um direito individual de todos, o qual possui o objetivo fundamental de construir uma sociedade livre e justa (BRASIL, 1988).

Em relação a criminalização da posse de drogas para consumo pessoal, é clara a violação ao princípio da liberdade, haja vista que a escolha afeta tão somente o próprio indivíduo e diz respeito a autonomia da vontade.

A liberdade é entendida como o poder de autodeterminação que a pessoa exerce sobre si, com livre escolha sobre seu corpo, pensamentos, comportamentos, vontades, tanto na ação quanto na omissão, estabelecendo suas próprias direções e escolhas (CANTALI, 2009).

Nesse sentido, José Afonso da Silva (2014, p. 233) afirma que: 
O direito à liberdade, de acordo com o nosso sistema jurídico constitucional, assegura a cada pessoa a possibilidade de autodeterminação, ou seja, o poder de autonomia, pelo qual ela escolhe por si mesmo o seu comportamento pessoal, de acordo com a sua consciência, os seus valores e os seus interesses, desde que não atinja a esfera pessoal de terceiro.

Diante do exposto, para que o Estado interfira na vida privada do indivíduo deve haver um fundamento legítimo e constitucional para tanto, o que não ocorre quanto ao uso da droga pela pessoa adulta e capaz no pleno exercício do direito à liberdade.

\subsection{PRINCÍPIO DA INTIMIDADE E VIDA PRIVADA}

Os direitos a intimidade e a vida privada estão explícitos na Constituição Federal, como direitos individuais e fundamentais, classificados como cláusulas pétreas pelo art. $5^{\mathrm{a}}$, inciso $X$ (BRASIL, 1988).

Intimidade é tudo o que diz respeito única e exclusivamente à pessoa, como o modo de ser e de agir em situações mais reservadas, com a exclusão de terceiros (TAVARES, 2010).

De acordo com José Afonso da Silva (2014, p. 210):

A tutela constitucional visa proteger as pessoas de dois atentados particulares: (a) ao segredo da vida privada; e (b) à liberdade da vida privada. O segredo da vida privada é condição de expansão da personalidade. Para tanto, é indispensável que a pessoa tenha ampla liberdade de realizar sua vida privada, sem perturbação de terceiros.

A intimidade e a vida privada estão relacionadas ao direito de privacidade, o qual determina um espaço da vida particular das pessoas sem a interferência de terceiros ou do próprio estado. A religião, os hábitos pessoais fazem parte da intimidade do cidadão, os quais devem ficar na esfera da decisão e discricionaridade de quem os praticou. Se um indivíduo bebe até cair desmaiado na cama, ou fuma uma carteira de cigarro entre o jantar e a hora de dormir, não parece bom, mas não é ilícito. O mesmo acontece com fumar um cigarro de maconha, é ruim, mas não é papel do Estado interferir nesta área (MALUF, 2016). 


\section{A INCONSTITUCIONALIDADE DA CRIMINALIZAÇÃO DA POSSE DE DROGAS PARA CONSUMO PESSOAL}

A Lei 11.343/2006 trouxe várias inovações, entre elas o tratamento diferenciado entre o usuário e o traficante de drogas, bem como, a exclusão de pena privativa de liberdade e multa para o usuário, dando lugar a penas educativas de advertência, prestação de serviços à comunidade e medida de comparecimento à programa ou curso (BRASIL, 2006). Contudo, manifestou-se ultrapassada ao criminalizar a posse de drogas para consumo pessoal, violando as diretrizes do Estado Democrático de Direito e da Constituição Federal.

A violação a um princípio é sem dúvidas a mais grave das inconstitucionalidades, porque sem princípio não há ordem constitucional e consequentemente, não há garantia dos direitos (BONAVIDES, 2003).

A questão constitucional pode ser levantada em processos de qualquer natureza, desde que haja um conflito de interesses, uma pretensão resistida, um ato de autoridade ou ameaça de que venha a ser praticado. O objeto não é o ataque a lei, mas a proteção de um direito que seria por ela violado (BARROSO, 2012).

Em defesa da inconstitucionalidade da criminalização da posse de drogas para consumo pessoal, Luiz Flávio Gomes afirma que a intervenção do direito penal deve ocorrer somente em casos graves e de alta relevância, quando houver lesão concreta ou real. Ocorre que o tipo penal analisado não ultrapassa o âmbito privado do agente (GOMES, 2013).

O Direito Penal não tem legitimidade de intervir nas decisões pessoais, bem como não pode impor padrão de comportamento que intensifica o desrespeito à diversidade (CARVALHO, 2010).

Para constituir fato típico, a atitude ultrapassa a esfera individual do agente e atinge $o$ interesse do outro. Ninguém pode ser punido por ter feito mal a si. Se a conduta não afeta o próximo, não há fato típico. Por esta razão a autolesão não é crime (CAPEZ, 2012).

A ação que não envolve perigo concreto, direto e imediato para terceiros diz respeito somente ao indivíduo, sua intimidade e suas escolhas pessoais, e não afeta nenhum bem jurídico alheio. Desta forma, o Estado não pode violar a vida privada do agente para criminaliza-lo pela conduta que diz unicamente a ele (KARAM, 2006). 
Ao criminalizar o porte de drogas para consumo pessoal, a lei afronta o direito da dignidade da pessoa humana, definida como a capacidade de autodeterminação das pessoas para o desenvolvimento da própria vida, onde seja possível a reciprocidade (GRECO, 2010).

A dignidade da pessoa humana é um dos princípios mais importantes da Constituição Federal, sendo considerado o cerne de todos os direitos fundamentais. A ideia deste direito fundamental é tratar cada indivíduo com um fim em si mesmo, e não como meio para a realização de metas coletivas (BARROSO, 2009).

Não há legitimidade na interferência do direito penal quando a conduta diz respeito apenas ao espaço de autodeterminação do agente, sem repercussão para terceiros. Desta forma, inexiste relevância penal na ação que cause apenas autolesão (BOTTINI, 2015).

Criminalizar a conduta da posse de drogas para uso próprio é mais um discurso de aparência do que de eficácia. Ao mesmo tempo que a Constituição Federal incentiva a autonomia e a liberdade, a lei infraconstitucional incrimina as escolhas das pessoas se estas são contrárias aos interesses moralmente dominantes (BIZZOTTO; RODRIGUES; QUEIROZ, 2010).

No mais, o tratamento diferenciado para usuários de diferentes substâncias tem muito mais a ver com interesses econômicos do que preocupação com a qualidade de vida dos indivíduos (BIZZOTTO; RODRIGUES; QUEIROZ, 2010).

Nesse sentido, ofende o princípio da igualdade o estabelecimento de distinção arbitrária de tratamento penal (drogas ilícitas) e não penal (drogas lícitas) para usuários de diferentes substâncias, sem que haja respaldo legal para tal diferenciação (CARVALHO, 2010).

Para Maria Lúcia Karam (2006) tais restrições políticas impostas pelo legislador afetam a noção de liberdade, bem como, o aperfeiçoamento humano. Para ela, o proibicionismo às drogas configura censura, visto que a criminalização desinforma, deseduca, oculta fatos, além de moldar opiniões conformistas e imobilizadoras.

A proteção da intimidade e da vida privada, abrangidas pela norma constitucional, conferem a possiblidade do indivíduo conduzir sua própria vida da maneira que julgar mais conveniente sem a intervenção de terceiros (NOVELINO, 2012). 
Ao consumir determinada droga, o indivíduo está fazendo uso de uma faculdade que Ihe é garantida pela Constituição, relacionada ao pluralismo político previsto em seu art. $1^{\circ}$. Está dispondo sobre seu próprio corpo, como estaria ao tentar um suicídio. A autolesão não é punida no ordenamento jurídico brasileiro, e assim deve ser considerada o uso de drogas, onde o único bem jurídico afetado é o próprio consumidor (HAMOY, 2009).

Diante do exposto, é evidente que a criminalização da posse de drogas para consumo próprio fere os princípios da igualdade e isonomia, intimidade e vida privada e da liberdade, direitos que decorrem do princípio fundamental da dignidade da pessoa humana, previstos na Constituição Federal.

Além das discussões sobre o tema na doutrina, encontra-se em andamento no Supremo Tribunal Federal o recurso extraordinário n. 635.659, em julgamento desde o ano de 2011, com repercussão geral, o qual analisa a constitucionalidade do art. 28 da lei 11.343/2006. Até o momento, três ministros proferiram seus votos, como veremos abaixo (BRASIL, 2011).

Em 2010, pela Defensoria Pública do Estado de São Paulo foi interposto Recurso Extraordinário n. 635.659, com o fim do Supremo Tribunal Federal declarar a inconstitucionalidade do art. 28 da Lei de Drogas, haja vista que não há lesão a saúde pública, a qual diverge do bem tutelado pelo dispositivo que tem como redação o consumo pessoal. Se caso fosse crime, pessoas que consomem bebidas alcoólicas ou outras drogas licitas também estariam lesando a saúde pública (CAPEZ, 2012).

O ministro-relator Gilmar Mendes, ao iniciar o voto, afirma que a natureza do recurso se funda na incompatibilidade do art. $28 \mathrm{com}$ as garantias constitucionais, visto que o tipo penal criminaliza condutas que diriam respeito, tão somente, à vida privada do agente (BRASIL, 2015).

Para o ministro, a criminalização do porte de drogas para consumo pessoal é excessivamente agressiva à privacidade $\mathrm{e}$ à intimidade. $\mathrm{O}$ tratamento criminal a esse tipo de conduta rotula perigosamente o usuário, dificultando a inserção social (BRASIL, 2015).

[...] É sabido que as drogas causam prejuízos físicos e sociais ao seu consumidor. Ainda assim, dar tratamento criminal ao uso de drogas é medida que ofende, de forma desproporcional, o direito à vida privada e à autodeterminação. O uso privado de drogas é conduta que coloca em risco a 
pessoa do usuário. Ainda que o usuário adquira as drogas mediante contato com o traficante, não se pode imputar a ele os malefícios coletivos decorrentes da atividade ilícita (BRASIL, 2015, p. 36-37).

Ainda, afirma durante a prolação do voto, que a saúde pública não pode ser usada como fundamento para a interferência penal na vida privada, atingindo o desenvolvimento da personalidade do agente de forma desproporcional (BRASIL, 2015).

O ministro votou pela inconstitucionalidade do artigo 28 da Lei de Drogas, não apontando o tipo de substância ilícita, dando margem a interpretação de que se trata de todos as substâncias ilegais, mas optou por manter, até o surgimento de uma legislação específica, as medidas de natureza administrativas previstas em lei (BRASIL, 2015).

O ministro Edson Fachin também proferiu seu voto no RE, seguindo o relator sobre a inconstitucionalidade da norma em análise, mas limitando a declaração apenas a droga do caso concreto, ou seja, a cannabis sativa (maconha), sob a afirmação que a atuação fora dos limites circunstanciais do caso podem conduzir a intervenções judiciais desproporcionais (BRASIL, 2015).

Para o ministro, criminalizar o porte de droga para consumo pessoal representa a imposição de um padrão moral individual, dando uma falsa impressão de proteção da sociedade, haja vista que a criminalização não protege e nem previne que o agente faça o uso de drogas (BRASIL, 2015).

Ainda, para corroborar com o seu entendimento ao votar pela inconstitucionalidade, o ministro cita o posicionamento de Nino (1989), vejamos:

\begin{abstract}
Se as regras de um sistema moral individual que valorize a liberdade vedam que a conduta de um cidadão ofenda bens jurídicos alheios, elas, porém, não podem impor modelos de virtude pessoal e tampouco julgar as ações de um cidadão por seus efeitos sobre o caráter do próprio agente. Ou seja, os ideais de excelência humana que integram o sistema moral individual não devem ser impostos pelo Estado, mas devem ser produto de escolha de cada indivíduo. Essa é a liberdade fundamental que caracteriza a autonomia privada de cada sujeito, como soe acontecer nas sociedades liberais (NINO, 1989, p. 425 apud BRASIL, 2015, p. 03-04).
\end{abstract}

Por fim, concluiu o ministro por declarar a inconstitucionalidade da criminalização da posse de drogas para consumo pessoal, exclusivamente da droga objeto do RE, cannabis sativa, bem como manter a proibição as demais drogas ilícitas, 
e atribuiu ao legislativo o estabelecimento de quantidades mínimas para distinção entre usuário e traficante (BRASIL, 2015).

O ministro Luís Roberto Barroso vota a favor da inconstitucionalidade do tipo penal quanto ao uso da droga conhecida como maconha, determinando que sejam criados requisitos para a distinção de uso e de tráfico, para diminuir a discricionaridade judicial e uniformizar a aplicação da lei (BRASIL, 2015).

Barroso afirma que o consumidor não deve ser tratado como criminoso, mas como alguém que se sujeita a realizar um comportamento de risco, do qual se torna a principal vítima. Todavia, o risco não é fundamento para a criminalização, ou atividades como alpinismo e mergulho submarino deveriam ser banidas (BRASIL, 2015).

Para o ministro, a criminalização do porte de drogas para consumo pessoal aproxima o usuário do mundo do crime, dificultando o acesso a tratamento da dependência, comprometendo a saúde pública ao invés de protegê-la (BRASIL, 2015).

Ainda, sustenta que a liberdade é um valor essencial nas sociedades democráticas, e possui um núcleo intangível que é a autonomia individual. A autonomia assegura ao indivíduo a autodeterminação e o direito de fazer escolhas de acordo com suas próprias concepções (BRASIL, 2015).

Punir uma conduta que diz respeito somente a vida privada do agente é uma forma de autoritarismo praticado pelo Estado, que para poupar uma pessoa do risco, vive a vida dela. Outrossim, não havendo lesão a bem jurídico de terceiro, a criminalização do uso de maconha não se afigura legítimo (BRASIL, 2015).

Por fim, verifica-se que até o momento, três ministros proferiram seus votos junto ao recurso extraordinário dos quais os Ministros Luís Roberto Barroso e Edson Fachin votaram pela descriminalização da posse de drogas somente em relação a cannabis sativa (maconha), e o relator Gilmar Mendes votou pela descriminalização em relação a posse de todas as drogas (BRASIL, 2015).

Desta forma, verifica-se que o art. 28 da Lei de Drogas sofre vícios de constitucionalidade, haja vista ser ilegítimo a criminalização de pessoas adultas e capazes pelo consumo de uma substância, além de permitir a inferência estatal na vida privada dos indivíduos. 


\section{CONSIDERAÇÕES FINAIS}

O presente artigo versou uma breve discussão sobre a constitucionalidade da criminalização da posse de drogas para consumo pessoal. A lei infraconstitucional, em algumas situações, tal como no caso em tela, afasta o direito da livre escolha sobre a própria vida do indivíduo.

Nessa toada, o legislador se utilizou apenas de critérios morais a fim de proteger a saúde pública, afastando as questões de personalidade, de livre escolha, concluindo arbitrariamente em cercear o direito de tomar as próprias decisões, violando assim, direitos fundamentais, como a dignidade da pessoa humana, da igualdade, da liberdade e da intimidade e vida privada.

Parte da doutrina, bem como três ministros do Supremo Tribunal Federal também já se posicionam no sentido da inconstitucionalidade da criminalização sob a luz dos direitos fundamentais.

É necessário que o Estado se adeque a realidade social e aceite que a criminalização não é meio eficaz para afastar os indivíduos das drogas. Ainda, é fundamental a criação de critérios objetivos para a diferenciação de usuário e traficante, haja vista que esta obscuridade provoca a saturação do sistema penitenciário.

Assim, conclui-se que a liberdade de consumo é direito de todos desde que não exceda a esfera individual, mesmo que enseje riscos para a saúde do indivíduo. Desta forma, não há de se falar em crime ou em punibilidade, haja vista tratar-se de autolesão, conduta atípica para o Direito Penal.

Ante o exposto e, sob égide da Constituição Federal, resta claro que a lei infraconstitucional ao ferir os princípios constitucionais está contradizendo as bases da nossa Lei Maior, restando assim, inconstitucional o dispositivo que criminaliza a posse de drogas para consumo pessoal.

\section{REFERÊNCIAS}

AGOSTINI, Leonardo. Autonomia: fundamento da dignidade humana em Kant. 2009. Dissertação (Mestrado em Filosofia) - Pontifícia Universidade Católica do Rio Grande do Sul, Porto Alegre, 2009. Disponível em:

http://tede2.pucrs.br/tede2/handle/tede/2823. Acesso em 16 de jun de 2020. 
ANDREUCCI, Ricardo Antonio. Legislação penal especial. 3.ed. São Paulo: Saraiva, 2007. E-book.

BARROSO, Luís Roberto. O controle de constitucionalidade no direito brasileiro. 6.ed. São Paulo: Saraiva, 2012.

BARROSO, Luís Roberto. Curso de direito constitucional. São Paulo: Saraiva, 2009.

BITENCOURT, Cezar Roberto. Tratado do direito penal: parte geral. 23.ed. São Paulo: Saraiva, 2017.

BIZZOTTO, Alexandre; RODRIGUES, Andreia de Brito; QUEIROZ, Paulo.

Comentários críticos à lei de drogas. 3.ed. Rio de Janeiro: Lumen Juris, 2010.

BONAVIDES, Paulo. Curso de direito constitucional. 13.ed. São Paulo: Malheiros Editora, 2003.

\section{BOTTINI, Pierpaolo Cruz. Porte de Drogas para Uso Próprio e o Supremo}

Tribunal Federal. 1.ed. Rio de Janeiro: Viva Rio, 2015.

BRASIL. [Constituição (1988)]. Constituição da República Federativa do Brasil. Brasília, DF: Presidência da República, 1988. Disponível em: http://www.planalto.gov.br/ccivil_03/constituicao/constituicaocompilado.htm. Acesso em: 16 de jun de 2020.

BRASIL. Lei n. 11.343 de 23 de agosto de 2006. Institui o Sistema Nacional de Políticas Públicas sobre Drogas - Sisnad; prescreve medidas para prevenção do uso indevido, atenção e reinserção social de usuários e dependentes de drogas; estabelece normas para repressão à produção não autorizada e ao tráfico ilícito de drogas; define crimes e dá outras providências. Disponível em:

http://www.planalto.gov.br/ccivil_03/_ato2004-2006/2006/lei/l11343.htm. Acesso em: 16 de jun de 2020.

BRASIL. Supremo Tribunal Federal. Recurso extraordinário 635659 SP - São Paulo. Relator: Ministro Gilmar Mendes. Disponível em:

http://www.stf.jus.br/portal/jurisprudenciaRepercussao/verAndamentoProcesso.asp?i ncidente $=4034145 \&$ numeroProcesso $=635659$ \& classeProcesso $=R E \&$ numeroTema $=$ 506. Acesso em: 16 de jun de 2020.

CANTALI, Fernanda Borghetti. Direitos da Personalidade: disponibilidade relativa, autonomia privada e dignidade humana. Porto Alegre: Livraria do Advogado, 2009.

CAPEZ, Fernando. Curso de direito penal: legislação penal especial. 7.ed. São Paulo: Saraiva, 2012.

CARVALHO, José Ernani de Pacheco. Entorpecente: jurisprudência, prática, processo. 6.ed. Curitiba: Juruá, 1997. 
CARVALHO, Salo de. A política criminal de drogas no Brasil: estudo criminológico e dogmático da lei $n^{\circ} 11.343 / 2006$. 5.ed. Rio de Janeiro: Lumen Juris, 2010.

GONÇALVES, Victor Eduardo Rios. Legislação penal especial. 8.ed. São Paulo: Saraiva, 2011. E-book.

GOMES, Luiz Flávio. Lei de drogas comentada. 5.ed. São Paulo: Revista dos Tribunais, 2013. E-book.

GOMES, Luiz Flávio. Constituição Federal, Código Penal, Código de Processo Penal. 8.ed. São Paulo: Revista dos Tribunais, 2006.

GRECO, Luis. Posse de droga, privacidade, autonomia: reflexões a partir da decisão do Tribunal Constitucional argentino sobre a inconstitucionalidade do tipo penal de posse de droga com a finalidade de próprio consumo. Boletim Rbccrim, São Paulo, v.18, n.87, p. 84-102, nov./dez. 2010.

GRECO FILHO, Vicente; RASSI, João Daniel. Lei de drogas anotada: lei 11.343/2006. São Paulo: Saraiva, 2007. E-book.

HAMOY, Jr. Benjamin. A inconstitucionalidade do art. 28 da Lei 11.343/06 diante do arcabouço ideológico extraído da CF/88: Violação ao Princípio da Ofensividade. Disponível em http://ww3.lfg.com.br/public html/article.php? story=20090603153538912\&query=home. Acesso em: 16 de jun. 2020.

JESUS, Damásio de. Lei antidrogas: anotada: comentários à lei n. 11.343/2006. 10.ed. São Paulo: Saraiva, 2010. E-book.

KARAM, Maria Lúcia. A Lei 11.343/2006 e os repetidos danos do protecionismo. Boletim IBCCRIM, v. 14, n. 167, p. 7, out. 2006.

LOPES, Maurício Antônio Ribeiro. Princípios políticos do direito penal. São Paulo: Revista dos Tribunais, 1999.

MALUF, André Luiz. Critérios objetivos para o porte de drogas. Disponível em: https://www.jota.info/opiniao-e-analise/artigos/criterios-objetivos-para-o-porte-dedrogas-26112016. Acesso em: 16 de jun. 2020.

MARCÃO, Renato. Tóxicos: lei n. 11.343, de 23 de agosto de 2006 anotada e interpretada. 10.ed. São Paulo: Saraiva, 2015. E-book.

MASSON, Cleber. Direito penal esquematizado. 6.ed. Rio de Janeiro: Forense, 2012.

MORAES, Alexandre de. Direitos humanos fundamentais: teoria geral, comentários aos arts. $1^{\circ}$ a $5^{\circ}$ da Constituição da República Federativa do Brasil, doutrina e jurisprudência. 3.ed. São Paulo: Atlas, 2000. 
NOVELINO, Marcelo. Direito constitucional. 6.ed. São Paulo: Método, 2012.

NUCCI. Guilherme de Souza. Leis penais e processuais penais comentadas. 7.ed. São Paulo: Revista dos Tribunais, 2013. E-book.

ORGANIZAÇÃO MUNDIAL DE SAÚDE. OMS. Classificação de Transtornos Mentais e de Comportamento da CID-10: descrições clínicas e Diretrizes diagnósticas. Tradução Dorgival Caetano. 1.ed. Porto Alegre: Artes Médicas, 1993.

PAULINO, Wilson Roberto. Drogas: drogas psicotrópicas. São Paulo: Ática, 1999.

PIERANGELI, José Henrique. Códigos penais do Brasil: evolução histórica. 2.ed. São Paulo: Revista dos Tribunais, 2001. E-book.

RANGEL, Paulo; BACILA, Carlos Roberto. Lei de drogas: comentários penais e processuais. 3.ed. São Paulo: Atlas, 2015. E-book.

ROSA, Alexandre Morais da. Direito infracional: garantismo, psicanálise e movimento antiterror. Florianópolis: Habitus, 2005.

SARMENTO, Daniel. Dignidade da pessoa humana: conteúdo, trajetórias e metodologia. 1.ed. Belo Horizonte: Fórum, 2016. E-book.

SHECAIRA, Sérgio Salomão. Drogas: uma nova perspectiva. Boletim IBCCRIM, v. 22, n. 109, p. 235-250, jun. 2014.

SILVA, César Dario Mariano da. Lei de Drogas Comentada. 2.ed. São Paulo: Apmp - Associação Paulista do Ministério Público, 2016. Disponível em:

http://www.mpsp.mp.br/portal/page/portal/Escola_Superior/Biblioteca/Biblioteca_Virtu al/Livros_Digitais/APMP\%203330_Lei_de_drogas_Cesar\%20Dario.pdf. Acesso em: 16 de jun. 2020.

SILVA, José Afonso da. Curso de direito constitucional positivo. 37.ed. São Paulo: Malheiros, 2014.

TAVARES, André Ramos. Curso de Direito Constitucional. 8.ed. São Paulo: Saraiva, 2010.

ZISMAN, Célia Rosenthal. O princípio da dignidade da pessoa humana. São Paulo: IOB Thomson, 2005.

Artigo recebido em: 18/10/2020

Artigo aceito em: 09/11/2020

Artigo publicado em: 29/11/2021 